\title{
Anaerobic Capacity Changes of the National Freestyle Wrestlers during the Olympic Qualification Competition Period
}

\author{
Ozan Sever ${ }^{1}$, Süleyman Gönülateş ${ }^{2}$, Akan Bayrakdar ${ }^{3}$, Bilal Demirhan ${ }^{4}$, Serdar Geri ${ }^{4}$, Erdal Zorba ${ }^{3}$ \\ ${ }^{1}$ Faculty of Spor Sciences, Ataturk University, Erzurum, Turkey \\ ${ }^{2}$ Faculty of Spor Sciences, Pamukkale University, Denizli, Turkey \\ ${ }^{3}$ Faculty of Spor Sciences, Gazi University, Ankara, Turkey \\ ${ }^{4}$ Physical Education and Sports, Manas University, Bishkek, Kyrgzstan \\ Correspondence: Ozan Sever, Faculty of Sport Sciences, Ataturk University, Erzurum, 25050, Turkey.
}

Received: May 14, 2017

doi:10.11114/jets.v5i8.2423
Online Published: July 3, 2017

URL: https://doi.org/10.11114/jets.v5i8.2423

\begin{abstract}
This study aimed to evaluate the national level wrestlers' anaerobic capacity through the preparation and qualification periods for Rio 2016 summer Olympic Games. For this manner, 10 national level freestyle wrestlers'(age 22,10 $\pm 3,21$; weight $64,75 \pm 6,34$; height 164,31 $\pm 4,75)$ anaerobic outputs measured 3 times in three month intervals with Bosco repeated jump test. Peak Jump (cm), Flight time, average power, average power/weight, first $15 \mathrm{sec}$ average jump height, last $15 \mathrm{sec}$ average jump height, fatigue index scores analyzed with repeated measures Anova. Mean power/weight output of the wrestlers increased from $20,42 \mathrm{~W} / \mathrm{kg}$ to $21,28 \mathrm{~W} / \mathrm{kg}(4,21 \%)$ and fatigue index is decreased from 1,185 to $1,142(3,62 \%)$. However, this increase was not statistically significant $(\mathrm{p}<0,05)$. In six months of qualification and preparation period wrestlers' anaerobic capacity did not changed and it is thought to have been caused by some reasons such as having already reached a certain anaerobic peak level or athletes' competition level and frequency which might made it difficult for them to have a proper periodization during the year.
\end{abstract}

Keywords: anaerobic capacity, power, wrestling, repeated jump, fatigue

\section{Introduction}

The measurement of an athlete's physical performance through appropriate physiological testing provides the athlete, coach and trainer with information about the relative physical strengths, weaknesses, development, treatment etc. (Richard Hovey, 1989). Wrestling has several essential elements including high levels of dynamic and isometric strength, anaerobic and aerobic conditioning, quickness, flexibility, and power (Gierczuk, Hubner-Woźniak, \& Długolęcka, 2012). Since wrestling has multiple physiological-physical requirements, lots of scientific measurements are often used to evaluate these demands by coaches and athletes. One of the most important requirement for a wrestler is continuing the game under intense physiologic stress and disrupted homeostasis(Ho, 2013). For example, a freestyle wrestling match can elevate blood lactate concentrations in excess of $15 \mathrm{mmol} / \mathrm{L}$ and nearly $20 \mathrm{mmol} / \mathrm{L}$ in between 6 and 8 minutes (Horswill, 1992; W. J. Kraemer et al., 2001) which can lead serious muscle damage and fatigue(Ozkan \& Ibrahim, 2016). Wrestlers must be able to buffer the high-acidic muscle and blood concentrations in order to demonstrate optimal strength and power during training and competition (William Kraemer, Vescovi, \& Dixon, 2004). In such a case, physiological skills such as anaerobic capacity, anaerobic power, late fatigue and quick recovery, continue to compete in anaerobic stress become very important features. Unfortunately, there is no universally accepted method of evaluating these capacities relative to physical performance in wrestlers (Horswill, 1992). However continuous and repeated jump tests are using for evaluating anaerobic (mechanic) capacity and power for this manner in many studies. It has been shown that power output scores from the $15 \mathrm{~s}$ Bosco Jump test correlated well with ( $\mathrm{r}=0.86$, $\mathrm{P}<0.05)$ the percentage of fast twitch muscle fiber which effects the anaerobic work intensity and duration, obtained from the measurement of the vastus Iateralis muscle (C Bosco, Komi, Tihanyi, Fekete, \& Apor, 1983). In the same study $60 \mathrm{~s}$ jumping test demonstrated sensitivity in assessing fatigue among a group of subjects with similar fiber composition. That gives the idea that the continuous jumping test can be accepted by researchers as a test for estimation of human anaerobic power output and fatigue. The power output from the first $15 \mathrm{~s}$ of the Bosco test is measure of anaerobic power and the $>30$ s score is an indication of anaerobic capacity or endurance (Detanico, Pupo, Gheller, Dias, 
\& Dos Santos, 2013; Richard Hovey, 1989). Dotan proposed that a test of $30 \mathrm{~s}$ is more adequate than $60 \mathrm{~s}$ to anaerobic (glycolytic) capacity request, as it may contribute more effectively to maintain the subject driven during the entire test (Dotan, 2006). In addition, it is well known that most of the free wrestling training sessions involve resistance trainings with short rest to improve anaerobic capacity and resistance to fatigue (Fleck Steven J \& Kraemer William, 2014; W. Kraemer, Noble, Clark, \& Culver, 1987). For these reasons, this study aimed to evaluate these most important components' (anaerobic capacity and fatigue) change and development with 30s Bosco test thorough the preparation season of the national level Olympic athletes.

\section{Method}

\subsection{Subjects}

10 talented national level freestyle wrestlers who were in the Olympic qualification competitions and giving the struggle to qualify in the Olympic Games participated to the study. Detailed information about the study was given to the subjects before the measurements and the voluntary confirmation form get signed. The study protocol was approved by the ethics committee of Kyrgyzstan State Sports Academy (Ethics Committee no. 2017/115).

Table 1. Descriptive mean and standard deviations of participants

\begin{tabular}{llll}
\hline $\mathbf{n}$ & Age & Height (cm) & Body Weight (kg) \\
10 & $22,10 \pm 3,21$ & $164,31 \pm 4,75$ & $64,75 \pm 6,34$ \\
\hline
\end{tabular}

\subsection{Measurements}

Within the scientific project of the evaluation of Kyrgyzstan Olympic athletes, the measurements were repeated three times in January, May and September 2016. The Bosco et al. vertical jump test was used to evaluate mechanical power and capacity by measuring flight of consecutive vertical jumps during time intervals of 30 seconds. Repeated jumping data of the athletes were obtained by Fusion sport Smart jump brand jumping mat. Formula below with a 30 second version of the Bosco test used to calculate average power/weight scores of athletes(Carmelo Bosco, Luhtanen, \& Komi, 1983). The fatigue index is obtained by dividing the average jump height in the first 15 seconds by the average jump height in the last 15 seconds.

$$
\text { watts } / \mathrm{kg}^{-1}=\frac{\mathrm{g}^{2} \cdot \mathrm{Tf} \cdot \mathrm{Ts}}{4 \mathrm{n}(\mathrm{Ts}-\mathrm{Tf})}
$$

$\mathbf{g}^{2}=$ acceleration due to gravity $-(9.81 \mathrm{~m} / \mathrm{sec}), \mathbf{T f}=$ total flight time; $\mathbf{T s}=$ test duration $(\mathrm{sec}) \mathbf{n}=$ number of the jumps Bosco jump test formula(Carmelo Bosco et al., 1983).

\subsection{Statistical Analyze}

Repeated measure one-way variance analysis used for each variable with Spss 19 software and statistical significance was taken as 0.05 .

\section{Results}
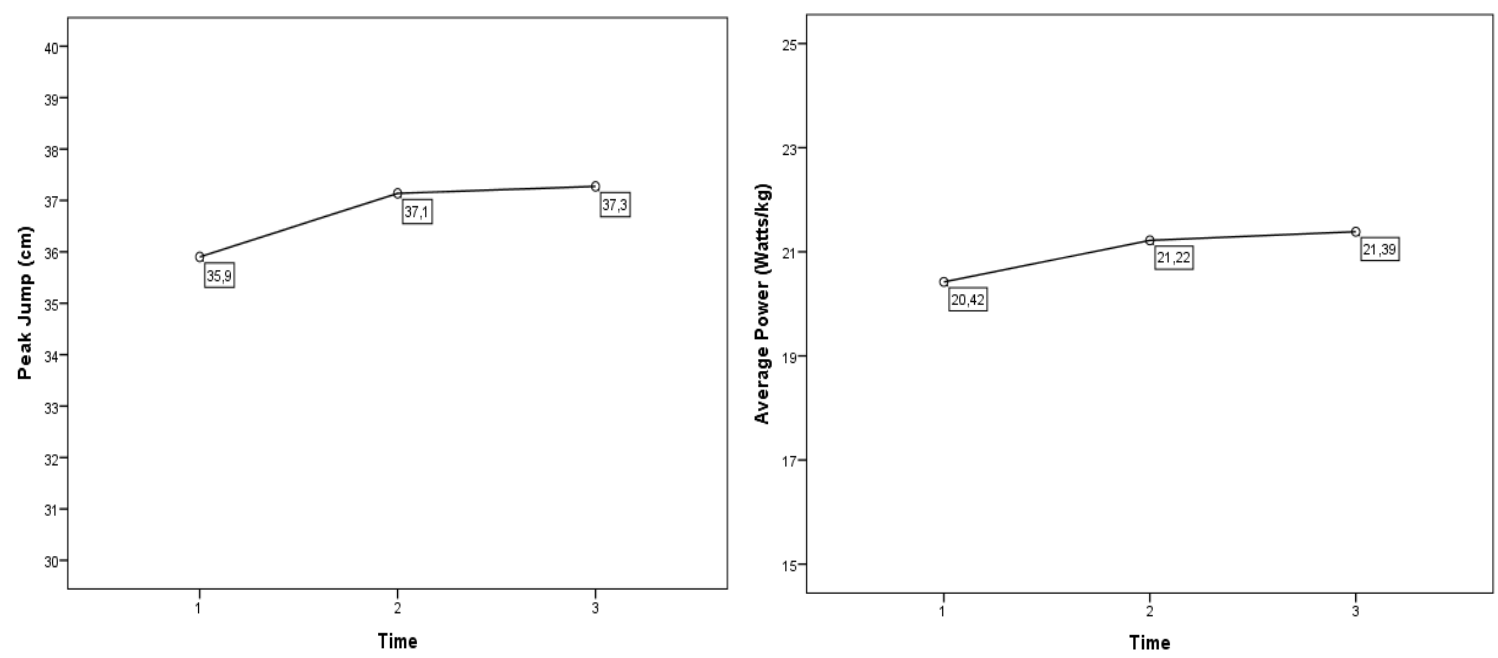

Figure 1. Peak jump and average power/kg means of wrestlers 
Table 2. Mean and std. dev. values of variables in 3 measurement periods.

\begin{tabular}{|c|c|c|c|c|c|}
\hline & \multicolumn{3}{|c|}{ Time } & \multirow{2}{*}{$\mathbf{F}$} & \multirow{2}{*}{$\mathbf{p}$} \\
\hline & 1 & 2 & 3 & & \\
\hline Weight $(\mathrm{kg})$ & $66,6 \pm 4,53$ & $66,5 \pm 4,48$ & $66,6 \pm 4,67$ & 0,231 & 0,796 \\
\hline Flight Time (ms) & $12761,6 \pm 909,5$ & $13071,0 \pm 919,1$ & $13084,9 \pm 1089,0$ & 0,662 & 0,528 \\
\hline Average Power/Weight (W/kg) & $20,42 \pm 1,56$ & $21,21 \pm 2,05$ & $21,38 \pm 2,22$ & 1,913 & 0,177 \\
\hline First $15 \mathrm{sec}$ Average Jump (cm) & $31,84 \pm 2,42$ & $32,82 \pm 2,47$ & $32,28 \pm 2,71$ & 1,192 & 0,326 \\
\hline Last $15 \mathrm{sec}$ Average Jump (cm) & $26,97 \pm 2,51$ & $28,11 \pm 3,71$ & $28,49 \pm 3,50$ & 3,190 & 0,065 \\
\hline Fatigue Index & $1,185 \pm 0,09$ & $1,179 \pm 0,10$ & $1,142 \pm 0,09$ & 1,710 & 0,209 \\
\hline
\end{tabular}

As it shown in figure and table, while average power, maximum jump, relative power per weight values are increased no statistical change has emerged for the wrestlers in three period outcomes of the preparation season for any variables.

\section{Discussion}

In the present study, the values obtained as a result of three measurement periods were not changed for any variables in qualification season of Olympic Games. Even if it seems that at least some improvement in performance variables this change is not statistically significant (Table 2). For example, average power/weight output increased from $20,42 \mathrm{~W} / \mathrm{kg}$ to $21,28 \mathrm{~W} / \mathrm{kg}$ and fatigue index is decreased from 1,185 to 1,142 . That means the percentage of power and fatigue index development were approximately 4,21 and 3,62. In a study which evaluates the seasonal change of anaerobic capacity; after four months training of soccer players, their average power output increased by $17 \%$ from a pre-season score of $20.8 \mathrm{~W} \backslash \mathrm{kg}$ to $24.3 \mathrm{~W} / \mathrm{kg}$ at mid-season(D. T. Kirkendall, 1985). This result explains the Bosco test was found to be reliable and sensitive in detecting changes in power output due to training. However, this limited development in the present study can be explained by the lack of training stimulus athletes exposed through the preparation season, the reduction of short-term power outputs because of incorrectly chosen training loads, the limited effect of training due to athletes' reaching of upper-limit performance thresholds or 60s variation of Bosco test. In this study we used 30s Bosco test, which is more practical and holds a more specific stimulus for sports that are acyclic and present the stretch-shortening cycle but it may be more invalid to show degree of fatigue (Detanico et al., 2013).

The mean relative power scores of the athletes in the present study tented to be developed more than other college wrestlers in one study in which wrestlers generated significantly less power than indoor soccer and basketball athletes (D. Kirkendall, 1986). In wrestlers, publications measuring anaerobic capacity with Bosco test are rare. Besides, comparing the results of the Bosco test with other anaerobic tests is difficult despite the high positive correlation between them (Viitasalo, L, Alen, P, \& E, 1987; William et al., 2004). The power output generated in the Bosco test is higher than, for example, the Wingate Anaerobic Test (e.g., 8,12 W/kg for international wrestlers in one study (Koçak \& Karli, 2003)), because the effect of the elastic energy and properties of jumping movement(Carmelo Bosco et al., 1983; William et al., 2004). In this regard, it was not possible to discuss the results of this study with similar publications. A variety of tests have been used in wrestlers as well as other athletes, making comparisons somewhat difficult (Horswill, 1992). In a study to determine successful wrestlers' profile for anaerobic power values are found as mean range of 6,1 to $7,5 \mathrm{~W} / \mathrm{kg}$ for arms and mean range of 7,5 to $19,9 \mathrm{~W} / \mathrm{kg}$ for legs with Margaria stair climb tests. Anaerobic capacity is ranged between 4,8 to 6 for arm cracking and 7,4 to 9,4 for Wingate tests in the same study (Horswill, 1992). But in studies with subjects from different athletic teams showed varied average power outputs in Bosco test which is between 18,79 to $26,6 \mathrm{~W} / \mathrm{kg}$ for volleyball, basketball, handball, footballers. (Carmelo Bosco et al., 1983; Hespanhol, Gonçalves, Neto, \& De Arruda, 2006; D. Kirkendall, 1986; Viitasalo et al., 1987). Bosco test's average power values of volleyball players and basketball players is higher than the other athletes in these studies may be explained as the jumping ability and using elastic energy kinetics is more developed in these athletes (Carmelo Bosco et al., 1983). As a result, in six months of qualification and preparation period wrestlers' anaerobic capacity did not changed and it is thought to have been caused by some reasons such as having already reached a certain anaerobic peak level or athletes' competition level and frequency which might made it difficult for them to have a proper periodization during the year.

\section{Acknowledgements}

This article has been produced from Kyrgyz-Turkey Manas University's KTMÜ-BAP: 2015.FBE.06 scientific research project. The project was supported by the Olympic Sports Directorate of the Ministry of Sports of Kyrgyzstan and Bishkek Coordinator of Turkish Cooperation and Coordination Agency (TIKA).

\section{References}

Bosco, C., Komi, P. V., Tihanyi, J., Fekete, G., \& Apor, P. (1983). Mechanical Power Test and Fiber Composition of Human Leg Extensor Muscles*. Eur. J. Appl. Physiol., 51(9623), 129-135. https://doi.org/10.1007/BF00952545

Bosco, C., Luhtanen, P., \& Komi, P. V. (1983). A Simple Method for Measurement of Mechanical Power in Jumping. Eur J Appl Physiol European Journal of Applied Physiology and Occupational Physiology, 50, $273-282$. 
https://doi.org/10.1007/BF00422166

Detanico, D., Pupo, J. D., Gheller, R. G., Dias, J. A., \& Dos Santos, S. G. (2013). Reliability Of The 30-S Continuous Jump Test For Anaerobic Fitness Evaluation: A Preliminary Study. In XXXIV Congress of the International Society of Biomechanics. Retrieved from https://isbweb.org/images/conferences/isb-congresses/2013/poster/ps1-13c.pdf

Dotan, R. (2006). The Wingate anaerobic test's past and future and the compatibility of mechanically versus electro-magnetically braked cycle-ergometers. European Journal of Applied Physiology, 98(1), 113-116. https://doi.org/10.1007/s00421-006-0251-4

Fleck, S. J., \& Kraemer, W. (2014). Designing Resistance Training Programs (4th ed.). Human Kinetics. Retrieved from https://books.google.com.tr/books?hl=tr\&lr=\&id=CczZAgAAQBAJ\&oi=fnd\&pg=PR1\&dq=Designing + Resistanc e+Training+Programs\&ots=kx4Gdva5iY\&sig=JLLhTYBe1oVWYA6T4qU73MrWLoA\&redir_esc =y\#v=onepage $\& \mathrm{q}=$ Designing Resistance Training Programs\&f=false

Gierczuk, D., Hubner-Woźniak, E., \& Długolęcka, B. (2012). Influence Of Training On Anaerobic Power And Capacity Of Upper And Lower Limbs In Young Greco-Roman Wrestlers. Biology of Sport, 29(3), 235-239. https://doi.org/10.5604/20831862.1003449

Hespanhol, J. E., Gonçalves, L., Neto, S., \& De Arruda, M. (2006). Reliability of the four series 15 -second vertical jumping test. Rev. Bras. Med. Esporte., 12(2). https://doi.org/10.2165/00007256-199214020-00004

Ho, L. A. (2013). Explosive Power and Anaerobic Endurance for Wrestlers. In 31 International Conference on Biomechanics in Sports. Retrieved from https://ojs.ub.uni-konstanz.de/cpa/article/viewFile/5521/5015

Horswill, C. A. (1992). Applied Physiology of Amateur Wrestling. Sports Medicine, 14(2), 114-143. https://doi.org/10.2165/00007256-199214020-00004

Kirkendall, D. (1986). Mechanical jumping power in athletes. British Journal of Sports Medicine, 20(4), 163-164. https://doi.org/10.1136/bjsm.20.4.163

Kirkendall, D. T. (1985). The Applied Sport Science of Soccer. The Physician and Sportsmedicine, 13(4), 53-59. https://doi.org/10.1080/00913847.1985.11708767

Koçak, S., \& Karli, U. (2003). Effects of high dose oral creatine supplementation on anaerobic capacity of elite wrestlers. The Journal of Sports Medicine and Physical Fitness, 43(4), 488-492. Retrieved from http://www.ncbi.nlm.nih.gov/pubmed/14767410

Kraemer, W. J., Fry, A. C., Rubin, M. R., Triplett-McBride, T., Gordon, S. E., Koziris, L. P., ... Fleck, S. J. (2001). Physiological and performance responses to tournament wrestling. Medicine and Science in Sports and Exercise, 33(8), 1367-1378. https://doi.org/10.1097/00005768-200108000-00019

Kraemer, W., Noble, B., Clark, M., \& Culver, B. (1987). Physiologic Responses to Heavy-Resistance Exercise with Very Short Rest Periods*. International Journal of Sports Medicine, 8(4), 247-252. https://doi.org/10.1055/s-2008-1025663

Kraemer, W., Vescovi, J., \& Dixon, P. (2004). The Physiological Basis of Wrestling: Implications for Conditioning. Strength and Conditioning Journal, 26(2). https://doi.org/10.1519/00126548-200404000-00001

Ozkan, I., \& Ibrahim, C. H. (2016). Dehydration, skeletal muscle damage and inflammation before the competitions among the elite wrestlers. Journal of Physical Therapy Science, 28(1), 162-168. https://doi.org/10.1589/jpts.28.162

Richard, H. (1989). Examination of Bosco Jump Test. McGill University . Retrieved from https://www.researchgate.net/profile/Richard_Hovey/publication/38433214_Examination_of_the_Bosco_jump_tes t/links/0deec52432e660b31c000000/Examination-of-the-Bosco-jump-test.pdf

Viitasalo, J., L, S., Alen, M., P, R., \& E, H. (1987). Mechanical jumping power in young athletes. Acta Physiologica Scandinavica, 131(1), 139-145. https://doi.org/10.1111/j.1748-1716.1987.tb08215.x

William, A., Jeni, R., Marshall, T. O., Terri, L., Monem, J., \& Michael, H. S. (2004). Comparison of Wingate and Bosco anaerobic tests. Journal of Strenght and Coniditioning Research, 18(4), 810-815. Retrieved from http://web.b.ebscohost.com/ehost/pdfviewer/pdfviewer?sid=74456fda-1381-4e18-84e0-660c498743ff\%40session mgr104\&vid $=0 \&$ hid $=116$

\section{Copyrights}

Copyright for this article is retained by the author(s), with first publication rights granted to the journal.

This is an open-access article distributed under the terms and conditions of the Creative Commons Attribution license which permits unrestricted use, distribution, and reproduction in any medium, provided the original work is properly cited. 